\title{
Atopy in cough sensitivity to capsaicin and bronchial responsiveness in young females
}

\author{
M. Fujimura*, K. Kasahara*, M. Yasui*, S. Myou*, Y. Ishiura*, Y. Kamio+, \\ T. Hashimoto**, T. Matsuda*
}

Atopy in cough sensitivity to capsaicin and bronchial responsiveness in young females. $M$. Fujimura, K. Kasahara, M. Yasui, S. Myou, Y. Ishiura, Y. Kamio, T. Hashimoto, T. Matsuda. CERS Journals Ltd 1998.

ABSTRACT: We have shown previously that female sex is a determinant of cough sensitivity to inhaled capsaicin, but the relationship between atopy and the cough sensitivity has not been examined.

The capsaicin cough threshold, defined as the lowest concentration of capsaicin causing five or more coughs, nonspecific bronchial responsiveness, defined as the provocative concentration of methacholine causing a $20 \%$ fall in the forced expiratory volume in one second (PC20), total immunoglobulin E (IgE) and specific IgEs to eigh common aeroallergens (house dust 1,2 and 6 , Dermatophagoides pteronyssinus and $D$. farinae, Japanese cedar, ragweed and orchard grass) in the serum were measured in 71 nonsmoking, healthy young women aged 20.6 \pm 0.1 yrs (mean \pm SEM). A structured interviewer-led questionnaire on allergic diseases revealed that one and six subjects had mild current and past asthma, respectively. These seven subjects were excluded from the data analysis.

PC20 was significantly lower in 42 subjects showing a positive specific IgE than in 22 subjects showing a negative specific IgE to any of the eight allergens $(p<0.05)$, while the capsaicin cough threshold was not significantly different between the subgroups. PC20 was significantly lower in subjects with positive specific IgE to Dermatophagoides and house dust, but not to the three kinds of pollen examined.

It was confirmed that atopy indicated by specific immunoglobulin $\mathbf{E}$ to mite-related antigens, but not to pollen antigens, is associated with nonspecific bronchial responsiveness, and it is suggested that atopy is not a determinant of airway cough sensitivity in healthy, nonasthmatic subjects. Eur Respir J 1998; 11: 1060-1063.
*Third Dept of Internal Medicine and ***Dept of Laboratory Medicine, Kanazawa University School of Medicine, Kanazawa, Japan. +Pulmonary Function Laboratory, Central Laboratory, Kanazawa University Hospital, Kanazawa, Japan.

Correspondence: M. Fujimura Third Dept of Internal Medicine Kanazawa University School of Medicine 13-1 Takara-machi

Kanazawa 920

Japan

Fax: 81762344252

Keywords: Airway cough sensitivity

atopy

capsaicin

nonasthmatic young females

nonspecific bronchial responsiveness specific immunoglobulin E

Received: September 251997 Accepted after revision February 91998

Supported in part by a Grant-in-Aid for Scientific Research from the Ministry of Education, Science and Culture (07670662 ) by the Japanese Government.
It has previously been reported that cough sensitivity to a chemostimulant, tartaric acid, which may produce cough by stimulating irritant receptors, is greater in young females than in young males [1]. In addition, it was shown recently that cough reflexing to capsaicin was more hypersensitive in females than in males, regardless of age, height, weight and pulmonary function [2]. The gender difference in cough sensitivity may explain why females are more susceptible to coughs induced by angiotensinconverting enzyme (ACE) inhibitors [3], and why chronic, persistent nonproductive cough which is resistant to bronchodilator therapy and in which eosinophils are detected in hypertonic saline-induced sputum [4], is more frequent in females [4-6].

It is well recognized that nonspecific bronchial responsiveness is associated with atopy indicated by allergen skin-prick tests [7-9] and serum specific immunoglobulin $\mathrm{E}$ (IgE) [10], but the association between airway cough sensitivity and atopy is not known. This study was designed to elucidate whether capsaicin-induced cough, which may depend on C-fibre afferents [11-13], is associated with atopy, expressed as serum-specific IgE to common aeroallergens, serum total IgE level and peripheral blood eosinophil count.
Subjects and methods

\section{Subjects}

Seventy-one, randomly selected, nonsmoking, female college students aged 20.6 \pm 0.1 yrs (mean \pm SEM), participated in this study. None of them had experienced upper respiratory tract viral infections for at least 8 weeks before or during the study period. The study was approved by the Ethics Committee of Kanazawa University, and informed consent was obtained from all subjects after the purpose of the test had been explained.

\section{Assessment of atopy}

Based on a structured, interviewer-led questionnaire, each subject was asked about respiratory symptoms, complicated allergic diseases and a past and family history of allergic diseases such as bronchial asthma, allergic rhinitis, atopic dermatitis and urticaria. 
Total white blood cell and eosinophil counts were performed according to a standard method. The serum total IgE level and specific IgE to eight common aeroallergens were measured by the radioimmunosorbent test (RIST) and the CAP method (Pharmacia, Uppsala, Sweden). A participant was considered as having measurable specific serum IgE when the response level was $>0.35 \mathrm{IU} \cdot \mathrm{mL}^{-1}$ to any of the following allergens: house dust 1,2 , or 6 , D. pteronyssinus, D. farinae, ragweed, Japanese cedar or orchard grass.

\section{Assessment of cough sensitivity to capsaicin}

Measurement of cough threshold to inhaled capsaicin was carried out using the method reported previously [2, 4, 6]. Capsaicin $(30.5 \mathrm{mg})$ was dissolved in Tween 80 (1 $\mathrm{mL})$ and ethanol $(1 \mathrm{~mL})$ and then dissolved in physiological saline $(8 \mathrm{~mL})$ to provide a stock solution of $1 \times 10^{-2}$ $\mathrm{M}$, which was stored at $-20^{\circ} \mathrm{C}$. This solution was diluted with physiological saline to make solutions of $0.49,0.98$, $1.95,3.9,7.8,15.6,31.2,62.5,125,250,500$ and 1,000 $\mu \mathrm{M}$. Each subject inhaled a control solution of physiological saline, followed by progressively increasing concentrations of the capsaicin solution. Solutions were inhaled for $15 \mathrm{~s}$ every $60 \mathrm{~s}$ by tidal mouth-breathing wearing a noseclip from a Bennett Twin nebulizer (3012-60 cc; Puritan-Bennett Co., Carlsbad. CA, USA) operated by compressed air at $5 \mathrm{~L} \cdot \mathrm{min}^{-1}$. Increasing concentrations were inhaled until five or more coughs were elicited. The output of the nebulizer was $0.21 \mathrm{~mL} \cdot \mathrm{min}^{-1}$. It has been reported that aerodynamic mass median diameter (MMD) of the particle is $3.60 \mu \mathrm{m}$, with a geometric standard deviation of 3.47 [14]. The number of capsaicin-induced coughs was counted by two medical technicians in the Pulmonary Function Laboratory of Kanazawa University. The cough threshold was defined as the lowest concentration of capsaicin that elicited five or more coughs.

\section{Assessment of nonspecific bronchial responsiveness}

Nonspecific bronchial responsiveness was evaluated by methacholine challenge. Methacholine chloride (Sigma Chemical Co., St Louis, MO, USA) was dissolved in physiological saline to make solutions of $0.04,0.08,0.16$, $0.31,0.63,1.25,2.5,5,10,20,40,80$ and $160 \mathrm{mg} \cdot \mathrm{mL}^{-1}$. Saline and methacholine were inhaled from a Devilbiss 646 nebulizer (Devilbiss Co, Somerset, PA, USA) operated by compressed air at $5 \mathrm{~L} \cdot \mathrm{min}^{-1}$. The output of the nebulizer was $0.28 \mathrm{~mL} \cdot 2 \mathrm{~min}^{-1}$. Firstly, saline was inhaled for $2 \mathrm{~min}$ and the forced expiratory volume in one second (FEV1) was measured on a dry wedge spirometer (Transfer Test; P.K. Morgan, Chatham, Kent, UK). After confirming that the change in FEV1 from the baseline after inhalation of saline was $ð 10 \%$ in all patients, the inhalation of methacholine was started. Methacholine was inhaled for $2 \mathrm{~min}$ by tidal mouth-breathing wearing a nose clip, followed immediately by spirometry. Methacholine of increasing concentrations was successively inhaled until a fall of $\mathrm{S} 20 \%$ in the FEV1 occurred. The measured values were plotted on semilogarithmic graph paper and the provocative concentration of methacholine producing a $20 \%$ fall in the FEV1 (PC20) was calculated.

\section{Data analysis}

One and six subjects were found to have current and past asthma, respectively, based on the questionnaire on allergic diseases and these seven subjects were excluded from the data analysis.

A PC20 ð $10 \mathrm{mg} \cdot \mathrm{mL}^{-1}$ was defined as bronchial hyperresponsiveness [15]. Fourteen of 64 nonasthmatic subjects (21.9\%) had bronchial hyperresponsiveness. The number of nonasthmatic subjects with a capsaicin cough threshold of $ð 1.95 \mu \mathrm{M}$, ð3.9 $\mu \mathrm{M}$ and $ð 7.8 \mu \mathrm{M}$ was 4,14 and 31 , respectively. Considering the proportion of subjects with bronchial hyperresponsiveness, cough hypersensitivity in this study was defined as a capsaicin cough threshold of ð3.9 $\mu \mathrm{M}$.

Values of the capsaicin cough threshold, PC20 and total $\mathrm{IgE}$ in the serum were expressed as geometric means with the geometric standard error of the mean (GSEM) expressed as a factor. Logarithmically converted values of the capsaicin cough threshold, PC20 and serum IgE were used in assessing the relationships and differences between these by simple regression analysis and analysis of variance (ANOVA), respectively. Chi-squared analyses of contingency tables were also used to determine the degree of association between variables. A p-value of $<0.05$ was taken as significant.

The odds ratio (OR) was used as an effect estimator to measure associations in this cross-sectional study [16]. In a situation in which exposure to a given factor is believed to be a cause of a given disease (or other outcome), the population attributable risk is the proportion of the disease (i.e. bronchial hyperresponsiveness and cough receptor hypersensitivity) in the total population that can be attributed to exposure to the factor (atopy). This estimator was calculated with regression techniques using the logic link for OR [16].

\section{Results}

\section{Cough sensitivity}

A capsaicin cough threshold was obtained in all 64 nonasthmatic subjects. The serum total IgE level, specific IgE to any of the allergens, peripheral blood eosinophil count, pulmonary function and PC20 were not significantly different between the 14 subjects with and 50 subjects without cough hypersensitivity. The cough threshold was not correlated with total IgE, peripheral blood eosinophil count or PC20. Furthermore, the cough threshold was not significantly different between subjects with and without positive specific IgE to either of the examined aeroallergens (table 1).

OR and $95 \%$ confidence intervals of cough hypersensitivity for specific IgEs are presented in table 2. An approximately twofold excess risk of cough hypersensitivity was observed in subjects with specific IgE to D. pteronyssinus $(\mathrm{OR}=2.00)$ and ragweed $(\mathrm{OR}=2.61)$, but this was not statistically significant.

\section{Bronchial responsiveness}

A $20 \%$ or greater fall in FEV1 was not obtained by the final concentration of methacholine $\left(160 \mathrm{mg} \cdot \mathrm{mL}^{-1}\right)$ in 20 
Table 1. - Cough sensitivity and bronchial responsiveness in nonasthmatic young females with positive and negative specific $\lg E$ in the serum

\begin{tabular}{|c|c|c|c|c|c|c|}
\hline & \multicolumn{2}{|c|}{ Number of subjects } & \multicolumn{2}{|c|}{ Capsaicin cough threshold $\mu \mathrm{M}$} & \multicolumn{2}{|c|}{$\mathrm{PC} 20 \mathrm{mg} \cdot \mathrm{mL}^{-1}$} \\
\hline & Positive & Negative & Positive & Negative & Positive & Negative \\
\hline Dermatophagoides pteronyssinus & 28 & 36 & $9.5(1.19)$ & $12.4(1.19)$ & $17.8(1.35)^{* * * *}$ & $86.1(1.27)$ \\
\hline Dermatophagoides farinae & 19 & 45 & $9.7(1.25)$ & $11.6(1.16)$ & $14.0(1.39)^{* * *}$ & $69.7(1.26)$ \\
\hline House dust 1 & 20 & 40 & $10.3(1.22)$ & $11.4(1.17)$ & $15.7(1.43)^{* * *}$ & $68.5(1.26)$ \\
\hline House dust 2 & 14 & 50 & 10.0 & $11.4(1.15)$ & $11.4(1.44)^{* * *}$ & $62.8(1.25)$ \\
\hline House dust 6 & 19 & 45 & $9.7(1.25)$ & $11.6(1.16)$ & $14.0(1.39)^{* * *}$ & $69.7(1.26)$ \\
\hline Orchard grass & 25 & 39 & $10.6(1.20)$ & $11.3(1.18)$ & $35.3(1.39)$ & $49.3(1.32)$ \\
\hline Ragweed & 5 & 59 & $9.0(1.66)$ & $11.2(1.14)$ & $13.0(2.52)$ & $47.9(1.24)$ \\
\hline Japanese cedar & 16 & 48 & $13.1(1.26)$ & $10.4(1.16)$ & $40.1(1.53)$ & $44.4(1.28)$ \\
\hline Any of the above allergens & 42 & 22 & $9.8(1.15)$ & $13.8(1.26)$ & $31.0(1.30)^{*}$ & $82.0(1.37)$ \\
\hline
\end{tabular}

Values are shown as geometric means (SEM). IgE: immunoglobulin E; PC20: provocative concentration causing a $20 \%$ fall in the forced expiratory volume in one second. *: $\mathrm{p}<0.05 ; * * *: \mathrm{p}<0.001 ; * * * *: \mathrm{p}<0.0001$ by analysis of variance.

Table 2. - Association of cough sensitivity and bronchial responsiveness with specific IgE in the serum in nonasthmatic young females

\begin{tabular}{|c|c|c|c|c|c|c|}
\hline & \multicolumn{3}{|c|}{ Cough sensitivity } & \multicolumn{3}{|c|}{ Bronchial responsiveness } \\
\hline & \multicolumn{2}{|c|}{ Positive specific IgE \% } & \multirow[b]{2}{*}{$\begin{array}{l}\text { Odds ratio } \\
(95 \% \mathrm{CI})\end{array}$} & \multicolumn{2}{|c|}{ Positive specific IgE \% } & \multirow[b]{2}{*}{$\begin{array}{l}\text { Odds ratio } \\
(95 \% \mathrm{CI})\end{array}$} \\
\hline & $\begin{array}{c}\text { Hyper } \\
n=14\end{array}$ & $\begin{array}{c}\text { Nonhyper } \\
n=50\end{array}$ & & $\begin{array}{c}\text { Hyper } \\
n=14\end{array}$ & $\begin{array}{c}\text { Nonhyper } \\
n=50\end{array}$ & \\
\hline Dermatophagoides pteronyssinus & 57.1 & 40.0 & $2.00(0.6-6.6)$ & $71.4^{*}$ & 36.0 & $4.44 \#(1.3-15.3)$ \\
\hline Dermatophagoides farinae & 35.7 & 28.0 & $1.43(0.4-5.0)$ & 50.0 & 24.0 & $3.17 \quad(1.0-10.5)$ \\
\hline House dust 1 & 35.7 & 30.0 & $1.30(0.4-4.5)$ & $57.1^{*}$ & 24.0 & $4.22^{\#}(1.3-13.9)$ \\
\hline House dust 2 & 21.4 & 22.0 & $0.97 \quad(0.2-4.2)$ & 35.7 & 18.0 & $2.53 \quad(0.7-9.1)$ \\
\hline House dust 6 & 35.7 & 28.0 & $1.43(0.4-5.0)$ & 50.0 & 24.0 & $3.17 \quad(1.0-10.5)$ \\
\hline Orchard grass & 28.6 & 42.0 & $0.55 \quad(0.2-2.0)$ & 28.6 & 42.0 & $0.55 \quad(0.2-2.0)$ \\
\hline Ragweed & 14.3 & 6.0 & $2.61(0.4-16.5)$ & 14.3 & 6.0 & $2.61 \quad(0.4-16.5)$ \\
\hline Japanese cedar & 14.3 & 28.0 & $0.43(0.1-2.1)$ & 28.6 & 24.0 & $1.27 \quad(0.3-4.8)$ \\
\hline Any of the above allergens & 71.4 & 64.0 & $1.41(0.4-5.1)$ & 78.6 & 62.0 & $2.25 \quad(0.6-8.9)$ \\
\hline
\end{tabular}

IgE: immunoglobulin E; CI: confidence interval. A capsaicin cough threshold of $ð 3.9 \mu \mathrm{M}$ was defined as cough hypersensitivity. Provocative concentration of methacholine causing a $20 \%$ fall in the forced expiratory volume in one second (PC 20$)$ of $\partial 10 \mathrm{mg} \cdot \mathrm{mL}^{-1} \mathrm{was}$ defined as bronchial hyperresponsiveness. *: $\mathrm{p}<0.05$ by Chi-squared analysis. \#: CI that do not contain the value 1.0 represent a significant increase in risk.

subjects and their $\mathrm{PC}_{20}$ values were assumed to be 320 $\mathrm{mg} \cdot \mathrm{mL}^{-1}$ for statistical analysis. PC20 was weakly correlated with total $\operatorname{IgE}$ level $(\mathrm{r}=0.322, \mathrm{p}<0.01)$, but not with the peripheral blood eosinophil count. Subjects with specific $\operatorname{IgE}$ to D. pteronyssinus $(\mathrm{p}<0.0001), D$. farinae $(\mathrm{p}<0.001)$, house dust $1(\mathrm{p}<0.001)$, house dust $2(\mathrm{p}<0.001)$, and house dust $6(\mathrm{p}<0.001)$, but not to any of pollen examined, had significantly lower PC20 than those without the specific IgEs (table 1).

OR and $95 \%$ confidence intervals of bronchial hyperresponsiveness for specific IgE are presented in table 2. An approximately twofold excess risk of bronchial hyperresponsiveness was observed in subjects with specific IgE to D. pteronyssinus $(\mathrm{OR}=4.44), D$. farinae $(\mathrm{OR}=3.17)$, house dust $1(\mathrm{OR}=4.22)$, house dust $2(\mathrm{OR}=2.53)$, house dust 6 $(\mathrm{OR}=3.17)$ and ragweed $(\mathrm{OR}=2.61)$. The prevalence of positive specific IgE to $D$. pteronyssinus and house dust 1 was significantly different $(\mathrm{p}<0.05)$ between subjects with and without bronchial hyperresponsiveness, respectively (table 2).

\section{Discussion}

The present study showed that the capsaicin cough threshold was not associated with atopy indicated by specific IgEs to eight common aeroallergens, serum total IgE level and peripheral blood eosinophil count in nonasthma- tic, healthy young females, and confirmed the association between nonspecific bronchial hyperresponsiveness and atopy, especially with specific $\operatorname{IgE}$ to $D$. pteronyssinus, $D$. farinae, house dust 1,2 and 6 , each of which is related to the mite antigen.

Cough reflex testing using capsaicin has been commonly used for studies on the pathophysiology of the cough reflex and antitussive effects of drugs. The reproducibility of sensitivity and of dose-response curve for capsaicininduced coughs has been established in normal subjects [17]. In this study, the cough threshold to inhaled capsaicin was measured as an index representing airway cough sensitivity, which was defined as the lowest concentration of capsaicin eliciting five or more coughs $[2,4,6]$. The reproducibility of the cough threshold was confirmed in a previous study in which the challenge was repeated at an interval of $30 \mathrm{~min}$ to 2 weeks in normal subjects $[18,19]$.

As some factors, such as sex [1, 2], menopause [2], cigarette smoking [1, 20-22] and ACE genotype [23], have been proposed to influence cough sensitivity, only nonsmoking, young females were examined to avoid the factors likely to influence cough sensitivity in the present study, whereas we did not examine the ACE genotype. In the results, i.e. atopy, indicated by specific IgEs to eight common aeroallergens, the serum total IgE level and peripheral blood eosinophil count, did not relate to cough sensitivity to inhaled capsaicin in nonasthmatic young females. 
It has been well established that there is an association between atopy, as a global feature and nonspecific bronchial hyperresponsiveness [7-10, 24]. In all of these studies, the association between atopy and bronchial hyperresponsiveness was analysed in the entire population including apparent current and past asthmatics. As it is well recognized that bronchial hyperresponsiveness is the fundamental feature of asthma as well as chronic airway inflammation, and there is a high prevalence of positive specific IgEs to aeroallergens in children and young adults with asthma [25], data analysis on bronchial responsiveness and atopy in a population is strongly influenced if subjects with asthma are included. Therefore, this study examined the association between atopy and nonspecific bronchial responsiveness to methacholine in a randomly selected population of young females. Current and past asthmatics were excluded based on a structured interviewer-led questionnaire on respiratory symptoms and allergic diseases.

The results confirmed the association between atopy and nonspecific bronchial hyperresponsiveness even in nonasthmatic subjects and showed that nonspecific bronchial hyperresponsiveness was significantly associated with specific IgEs to mite-related antigens but not to three kinds of pollen. Orchard grass, ragweed and Japanese cedar are the major allergens of pollinosis, but seldom cause asthma in Japan.

In conclusion, airway cough reflexes to inhaled capsaicin were not associated with atopy in nonasthmatic young females. The result is consistent with previous data showing that cough reflexing to inhaled tartaric acid is not heightened in asthma [26] and adds atopic status to the list of factors not directly influencing cough sensitivity, i.e. age, height, weight, pulmonary function [2], bronchomotor tone [15] and nonspecific bronchial responsiveness [26]. The independent factors that have been proven to exert an influence are sex, menopause [2], smoking history [1,20-22] and angiotensin-converting enzyme genotype [23].

Acknowledgements: The authors would like to thank W. Davidson, Dept of Biochemistry, Western General Hospital, Edinburgh, UK, for his kind advice in preparation of the manuscript.

\section{References}

1. Fujimura M, Sakamoto S, Kamio Y, Matsuda T. Sex difference in the inhaled tartaric acid cough threshold in non-atopic healthy subjects. Thorax 1990; 45: 633-634.

2. Fujimura M, Kasahara K, Kamio Y, Naruse M, Hashimoto T, Matsuda T. Female gender as a determinant of cough threshold to inhaled capsaicin. Eur Respir J 1996; 9: 1624-1626.

3. Gibson GR. Enalapril-induced cough. Arch Intern Med 1989; 149: 2701-2703.

4. Fujimura M, Songur N, Kamio Y, Matsuda T. Detection of eosinophils in hypertonic saline-induced sputum in patients with chronic nonproductive cough. J Asthma 1997; 34: 119-126.

5. Fujimura M, Sakamoto S, Matsuda T. Bronchodilatorresistive cough in atopic patients: bronchial reversibility and hyperresponsiveness. Intern Med 1992; 31: 447-452.

6. Fujimura M, Kamio Y, Hashimoto T, Matsuda T. Cough receptor sensitivity and bronchial responsiveness in patients with only chronic nonproductive cough: in view of effect of bronchodilator therapy. J Asthma 1994; 31: 463472.
7. Cockcroft DW, Murdock KY, Berscheid BA. Relationship between atopy and bronchial responsiveness to histamine in a random population. Ann Allergy 1984; 53: 26-29.

8. Peat JK, Salome CM, Woolcock AJ. Longitudinal changes in atopy during a 4-year period: relation to bronchial hyperresponsiveness and respiratory symptoms in a population sample of Australian schoolchildren. J Allergy Clin Immunol 1990; 85: 65-74.

9. Grainger DN, Stenton SC, Avery AJ, Duddridge M, Walters EH, Hendrick DJ. The relationship between atopy and non-specific bronchial responsiveness. Clin Exp Allergy 1990; 20: 181-187.

10. Soriano JB, Tobias A, Kogevinas M, et al. Atopy and nonspecific bronchial responsiveness: a population-based assessment. Am J Respir Crit Care Med 1996; 154: 16361640.

11. Coleridge HM, Coleridge JCG. Impulse activity in afferent vagal C-fibers with endings in the intrapulmonary airways of dogs. Respir Physiol 1977; 29: 125-142.

12. Fuller RW, Jackson DM. Physiology and treatment of cough. Thorax 1990; 45: 425-430.

13. Lundberg JM, Saria A. Capsaicin-induced desensitization of airway mucosa to cigarette smoke, mechanical and chemical irritants. Nature 1983; 302: 251-253.

14. Ryan G. Standardization of inhalation provocation tests: influence of nebulizer output, particle size, and method of inhalation. J Allergy Clin Immunol 1981; 67: 156-161.

15. Fujimura M, Kamio Y, Hashimoto T, Matsuda T. Log normal distribution of bronchial responsiveness to methacholine in normal young adults. Jpn J Physiol 1993; 43: $541-552$.

16. Lee J. Odds ratio or relative risk for cross-sectional data? Int J Epidemiol 1994; 23: 201-203.

17. Midgren B, Hansson L, Karlsson J, Simonsson BG, Persson GA. Capsaicin-induced cough in humans. Am Rev Respir Dis 1992; 146: 347-351.

18. Fujimura M, Kamio Y, Sakamoto S, Bando T, Myou S, Matsuda T. Tachyphylaxis to capsaicin-induced cough and its reversal by indomethacin, in patients with the sinobronchial syndrome. Clin Auton Res 1992; 2: 397-401.

19. Fujimura M, Sakamoto S, Kamio Y, Matsuda T. Effects of methacholine-induced bronchoconstriction and procate-rol-induced bronchodilation on cough receptor sensitivity to inhaled capsaicin and tartaric acid. Thorax 1992; 47: 441-445.

20. Rimpela A, Teperi J. Respiratory symptoms and low tar cigarette smoking: a longitudinal study on young people. Scand J Soc Med 1989; 17: 151-156.

21. Pounsford JC, Saunders KB. Cough response to citric acid aerosol in occasional smokers. Br Med J 1986; 293: 1528.

22. Taylor DR, Reid WD, Pare PD, Fleetham JA. Cigarette smoke inhalation patterns and bronchial reactivity. Tho$\operatorname{rax} 1988$; 43: 65-70.

23. Morice AH, Turley AJ, Linton TK. Human ACE gene polymorphism and distilled water induced cough. Thorax 1997; 52: 111-113.

24. Grainger DN, Stenton SC, Avery AJ, Duddridge M, Walters EH, Hendrick DJ. The relationship between atopy and non-specific bronchial responsiveness. Clin Exp Allergy 1990; 20: 181-187.

25. Platts-Mills TAE. Mechanisms of bronchial reactivity: the role of immunoglobulin E. Am Rev Respir Dis 1992; 145: S44-S47.

26. Fujimura M, Sakamoto S, Kamio Y, Matsuda T. Relationship between cough receptor sensitivity to inhaled tartaric acid and bronchial responsiveness to methacholine in normal and asthmatic subjects. Eur Respir J 1992; 5: 291-295. 